\title{
Cardiac dimensions and myocardial function of infants with congenital hypothyroidism An echocardiographic study
}

\author{
J C FOURON, J H BOURGIN, J LETARTE, J H DUSSAULT, G DUCHARME, A DAVIGNON \\ From the Cardiology and the Endocrinology Sections, Departments of Pediatrics and Pediatric Research, \\ Sainte-Fustine Hospital and University of Montreal, Canada
}

SUMMARY This study was undertaken to evaluate the cardiac dimensions and various indices of myocardial function, determined by echocardiography, in a group of 12 infants with congenital hypothyroidism. Left ventricular systolic and diastolic dimensions, posterior wall thickness, enddiastolic and systolic volumes were all significantly lower in the hypothyroid infants compared with 25 normal infants of the same age. No pericardial effusion was found. Hypothyroid infants had a lower heart rate with a reduced cardiac output. The mean velocity of circumferential fibre shortening and the shortening fraction of the left ventricle were normal. The pre-ejection period of the left ventricle (PEP), however, was abnormally prolonged as well as the ratio PEP over left ventricular ejection time (PEP/ET). This ratio correlated inversely with the end-diastolic volume, suggesting that the increased PEP/ET could be partly the result of decreased preload.

Several screening programmes have indicated that congenital hypothyroidism can be successfully detected during the first weeks of life, preventing irreversible cerebral damage. ${ }^{1}$ To our knowledge, no data are available concerning the cardiac size and myocardial function of these infants. Because of the structural and functional differences between neonatal and adult myocardial tissue, ${ }^{23}$ extrapolations from studies carried out in adults ${ }^{4}$ or older children ${ }^{5}$ must be made with great caution. Furthermore, the possibility that early diagnosis and treatment could minimise myocardial involvement and be an added benefit to the screening programme deserved investigation. We wish to report the cardiac dimensions and various indices of myocardial function, determined by echocardiography, in a group of newborn infants with congenital hypothyroidism. For comparison, the same echocardiographic study was performed on 25 normal infants of the same age.

\section{Subjects and methods}

The procedure according to which patients are screened and recalled in the Quebec screening programme for neonatal hypothyroidism has previously

Accepted for publication 23 February 1982 been described. ${ }^{67}$ Twelve infants aged 3 to 9 weeks (mean age 5.4 weeks) detected by this network were included in the study. The study procedure, applied to all patients on the day of the first visit, has also been published ${ }^{7}$ and includes the establishment of a clinical hypothyroid index (Table 1), chest and lower limbs $x$-rays (to evaluate the surface area of distal femoral ossification centres), and analysis of plasma T3, T4, and TSH. To this routine evaluation was added the recording of an echocardiogram.

Echocardiograms were recorded on an Ekoline model 20A ultrasonoscope interfaced with a Honeywell Cambridge fibreoptic recorder. An electrocardiogram with a well-defined $Q$ wave was simultaneously recorded. A $5 \mathrm{MHz}$ unfocused transducer was used in all patients. The following left ventricular systolic time intervals were measured ${ }^{8}$ : the pre-ejection period (PEP) from the onset of the QRS complex to the opening of the aortic valve; the ejection time (ET) from the opening to closure of aortic valves; and the ratio PEP/ET. Posterior wall and septal thickness in diastole, and systolic (LVIDs) and diastolic (LVIDd) internal dimensions of the left ventricular cavity were also measured. These measurements were made according to the recommendations of the American Society of Echocardiography. ${ }^{9}$ From the left ventricular internal dimensions, the following indices 
Table 1 Clinical signs and symptoms used for the hypothyroid clinical index score (for details see Reference 6)

Hernia
Feeding problems
Hypotonia
Constipation
Tongue
Inactivity
Skin mottling
Dry skin
Fontanelle
post. $<0.5 \mathrm{~cm}$
Typical facies

were calculated: the shortening fraction of the LV (SF=LVIDd-LVIDs/LVIDd), and mean velocity of circumferential fibre shortening (mean $\mathrm{VCF}=($ LVIDd - LVIDs $) /($ LVIDd $\times$ ET $))$, expressed in circumferences per second. Systolic and diastolic volumes of the left ventricle were calculated according to the cube formula, ${ }^{10}$ allowing evaluation of cardiac output and stroke volume. All measurements were made to the nearest $5 \mathrm{~ms}$ at a paper speed of 100 $\mathrm{mm} / \mathrm{s}$. In all patients, at least five different measurements were made for each value. In order to establish a control group, the same echocardiographic study was carried out in 25 normal infants aged 4 to 8 weeks. In this group, ejection time but not preejection period strongly correlated with heart rate $(r=-0.76)$. The difference between the ejection time observed in the hypothyroid group and that predicted by the regression equation calculated from our normal data for the appropriate heart rate was expressed as the change in this interval in milliseconds $(\triangle \mathrm{ET})$. (Predicted LVET $=331.4-0.933 \mathrm{HR}, \mathrm{p}<0.05$.)

Statistical comparison between the echocardiographic data of the hypothyroid patients and that of the normal group was made by unpaired $t$ test. Regression analysis was utilised to evaluate the correlations between the indices of myocardial function which were altered and the clinical index and the thyroid funtion tests. Normal biochemical values for thyroid function have already been published. ${ }^{6}$

\section{Results}

\section{THYROID FUNCTION}

Clinical, radiological, and biochemical data for the 12 patients are summarised in Table 2.

\section{CARDIAC DIMENSIONS}

Echocardiographic measurements of the minor axis of the left ventricle and the volumes calculated for the hypothyroid and the normal groups are shown in Table 3. Ventricular systolic and diastolic echocardiographic dimensions of hypothyroid patients were significantly lower than those of the normal group $(p<0.05)$. This was also true for ventricular volumes
Table 2 Clinical, radiological, and biochemical characteristics of hypothyroid patients

\begin{tabular}{llcc}
\hline & $\begin{array}{l}\text { No of } \\
\text { patients }\end{array}$ & Mean & $S D$ \\
\hline Clinical index & 12 & $8 \cdot 1$ & $3 \cdot 2$ \\
T4 $(\mathrm{ng} / \mathrm{dl})^{\star}$ & 12 & $1 \cdot 8$ & $1 \cdot 74$ \\
T3 $(\mu \mathrm{g} / \mathrm{dl})^{\star}$ & 10 & 81 & 43 \\
TSH $(\mu \mathrm{U} / \mathrm{ml})^{\star}$ & 12 & 468 & 261 \\
Bone maturation delay (wk) & 12 & $9 \cdot 34$ & 2.62 \\
$\quad$ Distal femoral & 12 & 10.37 & $2 \cdot 25$ \\
\hline Proximal tibial & 12 & \\
\hline
\end{tabular}

${ }^{\star}$ Normal values. ${ }^{6}$ Clinical index: $0.6 \pm 0 \cdot 1, \mathrm{~T} 4$ (plasma thyroxine): 5-14 ng/dl, T3 (plasma triiodothyronine): $70-220 \mu \mathrm{g} / \mathrm{dl}$, TSH (thyrotropin-stimulating hormone): less than $20 \mu \mathrm{U} / \mathrm{ml}$.

Ábbreviation: SD, one standard deviation.

Table 3 Comparison between ventricular dimensions of hypothyroid patients and control group

\begin{tabular}{lllllll}
\hline & \multicolumn{2}{l}{ Hypothyroid } & & \multicolumn{2}{l}{ Control } & \multirow{2}{*}{$p$} \\
\cline { 2 - 3 } & Mean & $S D$ & & Mean & $S D$ & \\
\hline LVIDd (mm) & 19 & 2 & & 20 & 2 & $<0.05$ \\
LVIDs $\left(\mathrm{mm}^{3}\right)$ & 13 & 2 & & 14 & 2 & $<0.05$ \\
EDV $\left(\mathrm{cm}^{3}\right)$ & 7.1 & 2.1 & & 8.7 & 2.5 & $<0.1$ \\
ESV $\left(\mathrm{cm}^{3}\right)$ & 2.3 & 0.9 & & 3.1 & 1.1 & $<0.05$ \\
LVPWd $(\mathrm{mm})$ & 2.9 & 0.34 & & 3.3 & 0.48 & $<0.05$ \\
IVSDd $(\mathrm{mm})$ & 3.5 & 0.9 & & 3.4 & 0.5 & NS \\
\hline
\end{tabular}

Abbreviations: LVIDd, left ventricular internal diameter in diastole; LVIDs, left ventricular internal diameter in systole; EDV, enddiastolic volume; ESV, end-systolic volume; LVPWd, left ventricular posterior wall thickness in diastole; IVSDd, interventricular septal dimension in diastole.

and left posterior wall thickness. No difference was found for septal thickness. No patient had echocardiographic evidence of pericardial effusion.

\section{MYOCARDIAL PERFORMANCE}

Mean velocity of circumferential fibre shortening (mean VCF) as well as shortening fraction and stroke volume of the hypothyroid infants were normal (Table 4). The pre-ejection period, however, was prolonged $(p<0.02)$ as well as the ratio PEP/ET $(p<0.001)$. The ejection time measured was consistently shorter than that predicted for the appropriate heart rate (average $\Delta \mathrm{ET}$ of $24 \mathrm{~ms}$ ). Heart rate was also significantly lower $(p<0.001)$ and cardiac output was decreased when compared with normal $(\mathrm{p}<0.02)$ (Table 4).

\section{CORRELATION STUDIES}

The correlation coefficients between abnormal echocardiographic variables and biological data are shown in Table 5. The clinical index of hypothyroidism was the only variable which correlated not only with systolic time intervals but also with ventricular 
Table 4 Comparison between myocardial performance of hypothyroid patients and control group

\begin{tabular}{|c|c|c|c|c|c|}
\hline & \multicolumn{2}{|c|}{$\begin{array}{l}\text { Hypothyroid } \\
\text { (No.12) }\end{array}$} & \multicolumn{2}{|c|}{$\begin{array}{l}\text { Control } \\
(\text { No.25) }\end{array}$} & \multirow[t]{2}{*}{$p$} \\
\hline & Mean & $S D$ & Mean & $S D$ & \\
\hline $\begin{array}{l}\text { Heart rate } \\
\text { SF } \\
\text { Mean VCF (circ/s) } \\
\text { PEP (ms) } \\
\text { PEP/ET } \\
\text { CO (1/min) } \\
\text { EF } \\
\text { SV (ml) }\end{array}$ & $\begin{array}{l}132 \\
0.31 \\
1.69 \\
66 \\
0.36 \\
0.63 \\
0.66 \\
4.8\end{array}$ & $\begin{array}{l}19 \\
0.08 \\
0.42 \\
11 \\
0.06 \\
0.27 \\
0.11 \\
1.8\end{array}$ & $\begin{array}{l}153 \\
0.30 \\
1.6 \\
57 \\
0.31 \\
0.87 \\
0.64 \\
5.6\end{array}$ & $\begin{array}{l}16 \\
0.06 \\
0.36 \\
7 \\
0.02 \\
0.26 \\
0.09 \\
1.8\end{array}$ & $\begin{array}{l}0.001 \\
\text { NS } \\
\text { NS } \\
0.02 \\
0.001 \\
0.02 \\
\text { NS } \\
\text { NS }\end{array}$ \\
\hline
\end{tabular}

Abbreviations: SD, one standard deviation; SF, shortening fraction of the left ventricle; mean VCF, mean velocity of circumferential fibre shortening; PEP, pre-ejection period; ET, ejection time; $\mathrm{CO}$, cardiac output; EF, ejection fraction; SV, stroke volume; NS, not significant.

Table 5 Correlation coefficients between echocardiographic variables, plasma T4, T3, and clinical index at time of diagnosis

\begin{tabular}{lrrr}
\hline Variables & \multicolumn{1}{c}{$T$ T } & \multicolumn{1}{c}{ T3 } & \multicolumn{1}{c}{ Index } \\
\hline Heart rate & 0.34 & 0.21 & -0.57 \\
PEP & -0.52 & -0.49 & 0.59 \\
PEP/ET & -0.65 & -0.71 & 0.57 \\
LVIDd & 0.41 & 0.39 & -0.62 \\
LVIDs & 0.14 & 0.41 & -0.59 \\
LVPWd & -0.34 & -0.54 & 0.76 \\
EDV & 0.40 & 0.32 & -0.57 \\
ESV & 0.19 & 0.51 & -0.60 \\
CO & 0.54 & 0.35 & -0.58
\end{tabular}

Abbreviations: as in Tables 3 and 4.

A positive or negative coefficient of 0.58 is significant at a $p$ value of 0.05 .

dimensions and cardiac output. There was also a significant correlation between the thyroid hormone plasma levels and the PEP/ET ratio.

\section{Discussion}

Severe hypothyroidism has long been known to produce abnormalities of cardiac structure and function in adults and children. In typical cases the myocardium is oedematous and basophilic with accumulation of mucopolysaccharides disrupting myocardial integrity. ${ }^{11} 12$ Clinically, bradycardia, reduced cardiac output, ${ }^{13}$ pericardial effusion, ${ }^{14}$ cardiomegaly, and dimished myocardial contractility ${ }^{15-17}$ are classical features. The effect, however, of decreased thyroid activity in utero on the cardiovascular condition of the newborn has never been specifically studied. Since the placenta is not permeable to TSH and T4, the fetus is completely autonomous as far as the hypothalamicpituitary-thyroid axis is concerned. Recent studies have suggested that this system is functionally mature at the end of the last trimester of gestation (phase III of fetal thyroid-system ontogenesis). ${ }^{18}$ To assess the influence of lack of thyroid hormone on the circulatory sytem during the first weeks of life, a non-invasive approach has been adopted in this study. The validity of echocardiography for myocardial function study and ventricular cavity measurements is now well established. ${ }^{19}$

Infants in this study had left ventricular cavities smaller than normal with no echocardiographic evidence of pericardial effusion. This finding is particularly significant in the presence of bradycardia that normally would tend to increase the end-diastolic volume. This suggests that the drop in the cardiac output and of the venous return is severe enough to counterbalance the increase in diastolic filling caused by lowering of the heart rate.

Results of myocardial function study of our hypothyroid patients seem to be contradictory. On one hand, PEP and PEP/ET have been found abnormally prolonged. This has been a consistent finding in all previous studies on hypothyroidism and interpreted as a sign of decreased myocardial contractility. ${ }^{161720}$ On the other hand, the ejection phase indices of ventricular performance such as mean VCF and shortening fraction were both within normal limits. This apparent contradiction can perhaps be explained by the fact that systolic time intervals (PEP, PEP/ET) are influenced not only by intrinsic myocardial contractility but also by changes in preload and/or afterload of the ventricles. ${ }^{21}$ In this study, cardiac output has been reduced. It has previously been shown that this low blood flow is essentially the result of the depressed metabolic requirements of the body. ${ }^{1322} \mathrm{~A}$ low cardiac output is necessarily associated with a fall in the venous return to the heart and consequently a decrease in the preload of the ventricle. This decrease in preload could, at least partly, explain the lengthening of the pre-ejection period and the abnormal PEP/ET ratio which were observed in our group of patients. To verify this hypothesis, we have studied the correlation betwen the PEP/ET ratio and the diastolic volume of the left ventricle, which is a reliable reflection of its preload. Though the number of patients is too small to allow any definitive conclusion, the results presented in the Figure show that left ventricular volume is inversely related to PEP/ET ratio. A completely different situation would be observed in primary myocardial dysfunction, where the preejection period would indeed be prolonged but the cardiac chambers would also be enlarged. In contrast to the PEP/ET ratios, VCF and the shortening fraction are relatively unaffected by either an acute,,$^{23}$ or chronic ${ }^{24}$ alteration of the preload.

Definite signs of myocardial dysfunction are therefore not present in the hypothyroid neonate. This may be because of the different structural and functional characteristics of the neonatal myocardium. 


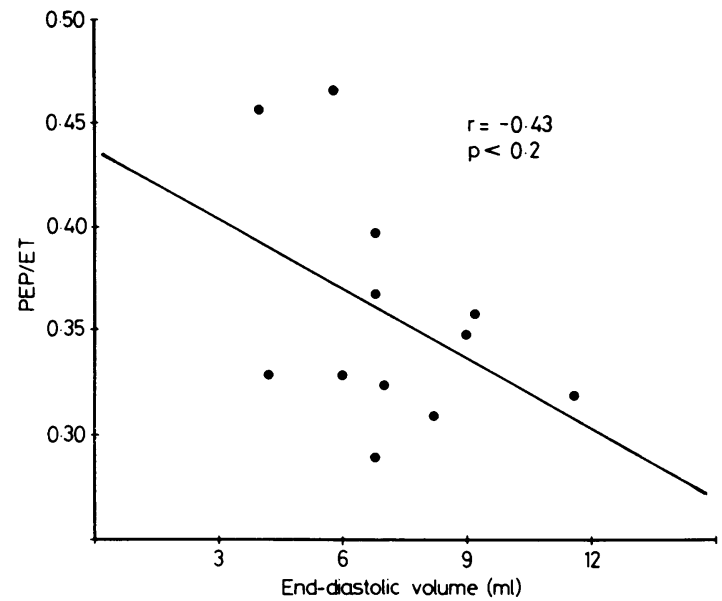

Fig. Relation between left ventricular pre-ejection period $(P E P) / l e f t$ ventricular ejection time (ET) and left ventricular end-diastolic volume (expressed in $\mathrm{ml}$ ).

\section{References}

1 Fisher DA, Dussault JH, Foley TP Jr, et al. Screening for congenital hypothyroidism: results of screening one million North American infants. $f$ Pediatr 1979; 94: 700-5.

2 Zak R. Cell proliferation during cardiac growth. Am $\mathcal{F}$ Cardiol 1973; 31: 211-9.

3 Romero T, Covell J, Friedman W. A comparison of pressure-volume relations of the fetal, newborn, and adult heart. Am F Physiol 1972; 222: 1285-90.

4 Symons C. Thyroid heart disease. Br Heart $\mathcal{F} 1979$; 41 : 257-62.

5 Hayford JT, Schieken RM, Thompson RG. Cardiac function in primary hypothyroidism. Am $\mathcal{F}$ Dis Child 1980; 134: 556-9.

6 Letarte J, Guyda H, Dussault JH. Clinical, biochemical, and radiological features of neonatal hypothyroid infants. In: Burrow GN, Dussault JH, eds. Neonatal thyroid screening. New York: Raven Press, 1980: 225-36.

7 Dussault JH, Morissette J, Letarte J, Guyda H, Laberge C. Modification of a screening program for neonatal hypothyroidism. I Pediatr 1978; 92: 274-7.

8 Hirschfeld S, Meyer R, Schwartz DC, Korfhagen J, Kaplan S. Measurement of right and left ventricular systolic time intervals by echocardiography. Circulation 1975; 51: 304-9.

9 Sahn DJ, DeMaria A, Kisslo J, Weyman AE. Recommendations regarding quantitation in $\mathrm{M}$-mode echocardiography: results of a survey of echocardiographic measurements. Circulation 1978; 58: 1072-83.
10 Feigenbaum H. Left ventricle. In: Echocardiography. 2nd ed. Philadelphia: Lea \& Febiger, 1976: 317.

11 LaDue JS. Myxedema heart: a pathological and therapeutic study. Ann Intern Med 1943; 18: 332-44.

12 Brewer DB. Myxedema: autopsy report with histochemical observations on the nature of the mucoid infiltrations. F Pathol Bacteriol 1951; 63: 503-12.

13 Ellis LB, Mebane JG, Maresh G, Hultgren HN, Bloomfield RA. The effect of myxedema on the cardiovascular system. Am Heart $\mathcal{F}$ 1952; 43: 341-56.

14 Kerber RE, Sherman B. Echocardiographic evaluation of pericardial effusion in myxedema. Circulation 1975; 52: 823-7.

15 Amidi M, Leon DF, DeGroot WJ, Kroetz W, Leonard JJ. Effect of the thyroid state on myocardial contractility and ventricular ejection rate in man. Circulation 1968; 38: 229-39.

16 Crowley WF Jr, Ridgway EC, Bough EW. Noninvasive evaluation of cardiac function in hypothyroidism: response to gradual thyroxine replacement. $N$ Engl $\mathcal{f}$ Med 1977; 296: 1-6.

17 Burckhardt D, Staub JJ, Kraenzlin M, Raeder E, Engel $\mathrm{U}$, Cloppenburg $\mathrm{P}$. The systolic time intervals in thyroid dysfunction. Am Heart $\mathcal{F}$ 1978; 95: 187-96.

18 Fisher DA, Klein AH. Thyroid development and disorders of thyroid function in the newborn. $N$ Engl $F$ Med 1981; 304: 702-12.

19 Parisi AF, Moynihan PF, Folland ED. Echocardiographic evaluation of left ventricular function. Med Clin North Am 1980; 64: 61-81.

20 Bough EW, Crowley WF, Ridgway EC, et al. Myocardial function in hypothyroidism - relation to disease severity and response to treatment. Arch Intern Med 1978; 138: 1476-80.

21 Weissler AM, Lewis RP, Leighton RF. The systolic time intervals as a measure of left ventricular performance in man. In: Yu D, Goodwin J, eds. Progress in cardiology. vol.1. Philadelphia: Lea \& Febiger, 1972: 155-83.

22 Graettinger JS, Muenster JJ, Checchia CS, Grissom RL, Campbell JA. A correlation of clinical and hemodynamic studies in patients with hypothyroidism. $\mathcal{F}$ Clin Invest 1958; 37: 502-10.

23 Rankin LS, Moos S, Grossman W. Alterations in preload and ejection phase indices of left ventricular performance. Circulation 1975; 51: 910-5.

24 Ross J Jr, McCullagh WH. Nature of enhanced performance of the dilated left ventricle in the dog during chronic volume overloading. Circ Res 1972; 30: 549-56.

Requests for reprints to Dr Jean-Claude Fouron, Sainte-Justine Hospital, 3175 Sainte-Catherine Road, Montreal, Quebec, Canada H3T 1C5. 